\title{
Ovarian Cancer and Primary Peritoneal Carcinoma Pathologic Distant Metastasis TNM Finding v7
}

National Cancer Institute

\section{Source}

National Cancer Institute. Ovarian Cancer and Primary Peritoneal Carcinoma Pathologic

Distant Metastasis TNM Finding v7. NCI Thesaurus. Code C89658.

A pathologic finding about one or more characteristics of ovarian cancer or primary peritoneal carcinoma, following the rules of the TNM AJCC v7 classification system as they pertain to distant metastases. There is no pathologic M0 for ovarian cancer or primary peritoneal carcinoma. 